\title{
Comparison of anthropometric-based equations for estimation of body fat percentage in a normal-weight and overweight female cohort: validation via air-displacement plethysmography
}

\author{
Derry Temple ${ }^{1}$, Romain Denis ${ }^{2}$, Marianne C Walsh ${ }^{3}$, Patrick Dicker ${ }^{4}$ and \\ Annette T Byrne 5,6 ,* \\ ${ }^{1}$ Centre for Exercise \& Nutrition Science, University of Chester, Chester, UK: ${ }^{2}$ Institute for Sport and Health, University \\ College Dublin, Dublin, Republic of Ireland: ${ }^{3}$ Institute of Food and Health, University College Dublin, Dublin, Republic \\ of Ireland: ${ }^{4}$ Department of Epidemiology and Public Health, Royal College of Surgeons in Ireland, Dublin, Republic \\ of Ireland: ${ }^{5}$ Department of Physiology and Medical Physics, Royal College of Surgeons in Ireland, 123 St Stephens \\ Green, Dublin 2, Republic of Ireland: 'University College Dublin School of Biomolecular \& Biomedical Science, UCD \\ Conway Institute, Dublin 4, Republic of Ireland
}

Submitted 22 January 2013: Final revision received 20 January 2014: Accepted 13 March 2014: First published online 16 April 2014

\begin{abstract}
Objective: To evaluate the accuracy of the most commonly used anthropometricbased equations in the estimation of percentage body fat (\%BF) in both normalweight and overweight women using air-displacement plethysmography (ADP) as the criterion measure.

Design: A comparative study in which the equations of Durnin and Womersley (1974; DW) and Jackson, Pollock and Ward (1980) at three, four and seven sites $\left(\mathrm{JPW}_{3}, \mathrm{JPW}_{4}\right.$ and $\mathrm{JPW}_{7}$ ) were validated against ADP in three groups. Group 1 included all participants, group 2 included participants with a $\mathrm{BMI}<25 \cdot 0 \mathrm{~kg} / \mathrm{m}^{2}$ and group 3 included participants with a $\mathrm{BMI} \geq 25 \cdot 0 \mathrm{~kg} / \mathrm{m}^{2}$.

Setting: Human Performance Laboratory, Institute for Sport and Health, University College Dublin, Republic of Ireland.

Subjects: Forty-three female participants aged between 18 and 55 years.

Results: In all three groups, the \%BF values estimated from the DW equation were closer to the criterion measure (i.e. ADP) than those estimated from the other equations. Of the three JPW equations, $\mathrm{JPW}_{3}$ provided the most accurate estimation of \%BF when compared with $\mathrm{ADP}$ in all three groups.

Conclusion: In comparison to ADP, these findings suggest that the DW equation is the most accurate anthropometric method for the estimation of \%BF in both normal-weight and overweight females.
\end{abstract}

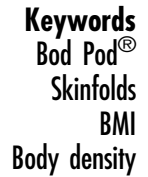

Keywords Skinfolds

Body density
Percentage body fat $(\% \mathrm{BF})$ is routinely measured in both clinical and sport science settings. An excess of body fat affects athletic performance and is frequently referred to as "dead weight"(1). In addition, it is well documented that surplus body fat has a negative impact on health ${ }^{(2)}$. In $2005,23 \cdot 2 \%$ of the world's adult population was estimated to be pre-obese and $9.8 \%$ obese $^{(3)}$. What was once considered a public health issue in first-world countries has now become a global epidemic. The currently reported rise in obesity levels has led to the need for reliable and valid measurements for estimating adiposity levels among different BMI groups and populations ${ }^{(4)}$. Various techniques are available to estimate \%BF. Whole-body air-displacement plethysmography (ADP) is an accurate and valid technique for the estimation of $\% \mathrm{BF}$ in human subjects $^{(5,6)}$ and is integrated in the $\operatorname{Bod~Pod}^{\circledR}$ system.
It is reliable ${ }^{(5,7)}$ and can quickly and safely evaluate body composition in a wide range of participants, including for instance vulnerable and/or obese populations that may pose practical difficulties ${ }^{(8,9)}$. Another technique used to estimate $\% \mathrm{BF}$ is the measurement of skinfold thickness. This technique indirectly measures the subcutaneous adipose tissue thickness at a specified site ${ }^{(10)}$ and is widely used in field settings ${ }^{(11)}$. The most commonly used equations to estimate body composition using the sum of skinfold thicknesses are those of Jackson, Pollock and Ward (1980; JPW) and Durnin and Womesley (1974; DW $)^{(12-14)}$. Several studies have noted an underestimation of \%BF using the DW and JPW equations in groups tested and this underestimation is particularly prevalent in female and obese populations ${ }^{(4,15,16)}$. Furthermore, in a study investigating children (aged 5-11 years), Michels et al. (2012) $)^{(17)}$ 
compared \%BF values estimated from skinfold-based equations against ADP. Interestingly, their results showed that \%BF estimated from equations used in children was increasingly underestimated with increasing \%BF in comparison to ADP. Thus, it is important to determine the accuracy of anthropometric-based equations for the estimation of \%BF in females compared with ADP, which is among the most reliable and valid techniques available. Therefore, the purpose of the current study was to compare the estimates of \%BF provided by the most commonly used skinfold-based equations against wholebody ADP in the general female population and in those with a $B M I \geq 25.0 \mathrm{~kg} / \mathrm{m}^{2}$ or $<25.0 \mathrm{~kg} / \mathrm{m}^{2}$. A secondary purpose was to determine which skinfold measurementbased equation provides the closest value to the criterion measure (i.e. ADP) for each group.

\section{Methods}

\section{Participants}

A total of forty-three Caucasian female participants were recruited from a university campus, fitness and slimming companies in the Dublin area. The study was conducted according to the guidelines laid down in the Declaration of Helsinki and all procedures involving human participants were approved by the University College Dublin Human Research Ethics Committee. Written informed consent was obtained from all participants.

Exclusion criteria included pregnancy and age under 18 years or over 55 years, as equations of JPW have been validated on females from within this age bracket. Participants were tested in the morning after fasting overnight and having defecated prior to testing, as considerable day-to-day variability of weight is attributable mainly to the intake and elimination of food and water ${ }^{(18)}$. Further, data were not collected from one week prior to commencement of a menstrual period and until the menstruation ended to avoid possible variation attributable to increases in the fluid content of fat-free mass ${ }^{(19)}$.
Assessments took place at the same time of the day, between 09.00 and 12.00 hours. Body composition assessments were performed on a single occasion, in a randomised order (i.e. whether skinfold callipers first or ADP first). Prior to body composition assessments, participants' height and body weight were measured to the nearest $0.1 \mathrm{~cm}$ using a wall-mounted stadiometer (Harpenden Stadiometer; Holtain Ltd, Crymych, UK) and to the nearest $0.2 \mathrm{~kg}$ on an electronic flat-bed scale (Seca 888; Seca, Hamburg, Germany), respectively. The stadiometer and body weight scale were calibrated before the beginning of the study. Participants had their skinfold thicknesses measured via Harpenden callipers (Holtain Ltd) and body volume was measured by ADP (Bod Pod ${ }^{\circledR}$; Life Measurements, Inc., Concord, CA, USA, software version 4.2-0). The skinfold thickness measurements were taken to estimate \%BF using the Durnin and Womersley (1974; four-site) ${ }^{(14)}$ and Jackson et al. (1980; three-, four- and seven-site) ${ }^{(13)}$ equations (see Table 1 for details).

\section{Testing procedure for estimation of percentage body fat using antbropometric equations}

Skinfold sites were located as described by Hawes and Martin ${ }^{(20)}$. Measurements were taken on participants wearing minimal clothing. Specifically, participants were instructed to wear swimming trunks, briefs, underwear or tight-fitting shorts. The right side of the body only was used for unilateral skinfold thickness measurements in order to maintain consistency in the measurement method. The tester pinched skin at the appropriate site to raise a double layer of skin and the underlying adipose tissue. The callipers were then applied $1 \mathrm{~cm}$ below and at right angles to the pinch, and a reading in millimetres was taken immediately. A minimum of two skinfold thicknesses were measured at each site in rotating order. Inconsistent skinfold thickness measurements ( $>2 \mathrm{~mm}$ ) were taken a third time ${ }^{(21)}$. The mean value was taken if two measurements were taken and the median value used if a third measurement was taken. Sites were measured in succession to avoid experimenter bias. A complete data

Table 1 Equations used in the present study for predicting body density of adult women. Sites and formulas for Jackson, Pollock and Ward's (1980) three-, four- and seven-site equations (JPW $3, \mathrm{JPW}_{4}$ and $\mathrm{JPW}_{7}$, respectively) and Durnin and Womersley's (1974) four-site equation (DW) are given

\begin{tabular}{|c|c|c|}
\hline Equation & Sites (skinfolds) & Formula \\
\hline $\mathrm{JPW}_{3}$ & Triceps, suprailliac, thigh & $\begin{array}{l}\text { Body density }=1.0994921-0.0009929\left(X_{3}\right)+0.0000023 \\
\left(X_{3}\right)^{2}-0.0001392(\text { Age })\end{array}$ \\
\hline $\mathrm{JPW}_{4}$ & Triceps, suprailliac, abdomen, thigh & $\begin{array}{l}\text { Body density }=1.096095-0.0006952\left(X_{2}\right)+0.0000011 \\
\left(X_{2}\right)^{2}-0.0000714(\text { Age })\end{array}$ \\
\hline $\mathrm{JPW}_{7}$ & $\begin{array}{l}\text { Chest, triceps, midaxillary, subscapular, } \\
\text { suprailliac, abdomen, thigh }\end{array}$ & $\begin{array}{l}\text { Body density }=1.097-0.00046971\left(X_{1}\right)+0.00000056 \\
\left(X_{1}\right)^{2}-0.00012828(\text { Age })\end{array}$ \\
\hline DW & Biceps, triceps, subscapular, suprailliac & 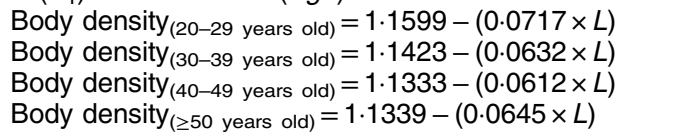 \\
\hline
\end{tabular}

Note: $X_{1}$ is sum of the seven skinfolds, $X_{2}$ is the sum of the four skinfolds and $X_{3}$ is the sum of the three skinfolds. $L$ is the log of the total of the four skinfolds. The formula of the DW equation is age dependent too (see different age categories in parentheses). 
set was consistently obtained before repeating measurements for a second or third time. Estimated \%BF was then calculated according to relevant equations.

\section{Testing procedure for estimation of percentage} body fat using air-displacement pletbysmography

Standard calibration procedures were followed prior to each ADP evaluation ${ }^{(22)}$. Participants were asked to wear minimal clothing as it can cause a significant underestimation of body volume and thus an overestimation of body density and underestimation of $\% \mathrm{BF}^{(22)}$. Therefore, participants were instructed to wear swimming trunks, briefs, underwear or tight-fitting shorts and a Lycra ${ }^{\circledR}$ swim cap. Shoes, jewellery and any other metal objects were removed prior to testing. When inside the chamber, participants were asked to sit in an upright position with hands placed on thighs and to sit still for the duration of the test. The participants' thoracic gas volume was predicted. The raw body volume of the participant was measured indirectly by measuring the volume of air displaced inside the enclosed chamber (i.e. the Bod Pod). Raw body volume values were used to calculate body density and were then applied to the Siri (1961) equation $^{(23)}$ to estimate $\% \mathrm{BF}$, i.e. $\% \mathrm{BF}=[(4.95 / \mathrm{body}$ density) $\times 100$ ]. Each test was repeated twice. The body volume measurement was repeated a third time if the two measures were not within $150 \mathrm{ml}$ of each other ${ }^{(22)}$.

\section{Statistical analyses}

Analyses were performed using the statistical software package SAS version 9.1. The root-mean-square error (RMSE), a measure of model fit, was used to determine the accuracy of the DW- and JPW-estimated \%BF relative to ADP estimation of \%BF. Hypothesis tests, which compare models, were not relevant since the model or true result is considered to be known (i.e. ADP). For comparability, the RMSE was normalized to the scale of measurement using the $\mathrm{CV}$ of the RMSE ( $\left.\mathrm{CV}_{\mathrm{RMSE}}\right)$. Skinfold measurements with smaller $C_{\text {RMSE }}$ represent body fat measures with reduced deviation from the ADP results (i.e. having greater accuracy). For any skinfold measure of \%BF, a sample size of forty-three was required to detect a minimum bias (difference between Bod Pod and skinfold measure) of $5 \%$ in body fat, assuming a standard deviation of $10 \%$ in body fat and $90 \%$ statistical power. Assuming a lower/ higher standard deviation to be true, then this sample size would require a proportional change in minimum bias that can be detected (e.g. a standard deviation of $8 \%$ body fat would allow us to confidently detect a bias of $4 \%$ ).

Statistical analysis was applied to three sets of data: (i) the entire sample group, this group was referred to as group 1 ( $n$ 43); (ii) in all participants from the sample with a BMI $<25 \cdot 0 \mathrm{~kg} / \mathrm{m}^{2}$, this group was referred to as group 2 ( $n$ 22); and (iii) in all participants from the sample with a BMI $\geq 25.0 \mathrm{~kg} / \mathrm{m}^{2}$, this group was referred to as group 3 ( $n$ 23).

Accuracy of body composition equations was compared within and between the groups. In addition to the assessment of accuracy in body fat measurements, estimates of bias from the equations were obtained by fitting simple linear regression models on the ADP measurements $($ bias $=$ intercept $+($ slope -1$) \times$ body fat $)$. The bias change-point, or point where bias is estimated to be 0 , can be determined from the regression analysis and indicates where the bias changes from positive to negative or vice versa.

\section{Results}

Skinfolds investigated, equations and formulas used in the present study are given in Table 1 . Measures of \%BF were analysed with descriptive statistics (mean, standard deviation) and are presented in Table 2 . The participants had a mean age, body mass, height and BMI of $37 \cdot 3$ years (sD 9.7 years), $70 \cdot 6 \mathrm{~kg}$ (sD $13.1 \mathrm{~kg}$ ), 164.3 (sD 7.7) $\mathrm{cm}$ and $26.2(\mathrm{sD} 5.4) \mathrm{kg} / \mathrm{m}^{2}$, respectively. The \%BF of group 1 using the DW equation $(\% \mathrm{BF}=32 \cdot 2(\mathrm{SD} 6 \cdot 6)$ ) was highly correlated to the \%BF estimated using $\mathrm{ADP}(\% \mathrm{BF}=32 \cdot 5$ (SD 10.4)). Accuracy of the values estimated from the JPW

Table 2 Participant characteristics and percentage body fat (\%BF) estimated using air-displacement plethysmography (ADP), Jackson, Pollock and Ward's (1980) three-, four- and seven-site equations (JPW $3, \mathrm{JPW}_{4}$ and JPW 7 , respectively) and Durnin and Womersley's (1974) four-site equation (DW) among forty-three females aged 18-55 years from Dublin, Republic of Ireland

\begin{tabular}{|c|c|c|c|c|c|c|c|c|c|}
\hline & \multicolumn{3}{|c|}{$\begin{array}{l}\text { All participants (group 1) } \\
\text { (n 43) }\end{array}$} & \multicolumn{3}{|c|}{$\begin{array}{c}\mathrm{BMI}<25.0 \mathrm{~kg} / \mathrm{m}^{2} \text { (group 2) } \\
(n 22)\end{array}$} & \multicolumn{3}{|c|}{$\begin{array}{c}\left.\mathrm{BMI} \geq 25.0 \mathrm{~kg} / \mathrm{m}^{2} \text { (group } 3\right) \\
(n 21)\end{array}$} \\
\hline & Mean & SD & Range & Mean & SD & Range & Mean & SD & Range \\
\hline Age (years) & $37 \cdot 3$ & $9 \cdot 7$ & $21 \cdot 0-54.0$ & 34.0 & 8.9 & $21 \cdot 0-54.0$ & $40 \cdot 8$ & $9 \cdot 6$ & $22 \cdot 0-52 \cdot 0$ \\
\hline Body mass $(\mathrm{kg})$ & $70 \cdot 6$ & $13 \cdot 1$ & $45 \cdot 5-109 \cdot 8$ & $62 \cdot 2$ & 8.7 & $45 \cdot 5-79.6$ & $79 \cdot 3$ & $11 \cdot 1$ & $63 \cdot 2-109 \cdot 8$ \\
\hline Height $(\mathrm{cm})$ & $164 \cdot 3$ & $7 \cdot 1$ & $148 \cdot 0-180 \cdot 0$ & $166 \cdot 8$ & 7.5 & $148 \cdot 0-180 \cdot 0$ & $161 \cdot 8$ & 5.7 & $151 \cdot 5-173.0$ \\
\hline BMI $\left(\mathrm{kg} / \mathrm{m}^{2}\right)$ & $26 \cdot 2$ & 5.4 & $16 \cdot 6-44 \cdot 5$ & $22 \cdot 3$ & $2 \cdot 2$ & $16 \cdot 6-24 \cdot 7$ & 30.4 & 4.6 & $25 \cdot 2-44.5$ \\
\hline$\% B F(A D P)$ & 32.5 & $10 \cdot 4$ & $10 \cdot 7-52 \cdot 6$ & $24 \cdot 8$ & $6 \cdot 3$ & $10 \cdot 7-36 \cdot 1$ & $40 \cdot 5$ & $7 \cdot 2$ & $24 \cdot 0-52 \cdot 6$ \\
\hline$\% B F\left(J P W_{3}\right)$ & $26 \cdot 8$ & 6.9 & $6 \cdot 9-37 \cdot 0$ & 21.6 & $5 \cdot 2$ & $6 \cdot 9-29 \cdot 6$ & $32 \cdot 3$ & 3.4 & $25 \cdot 7-37 \cdot 0$ \\
\hline$\% B F\left(J P W_{4}\right)$ & $25 \cdot 6$ & $6 \cdot 9$ & $8 \cdot 2-34 \cdot 7$ & $20 \cdot 8$ & 4.6 & $8 \cdot 2-28 \cdot 1$ & 30.7 & $3 \cdot 3$ & $23 \cdot 7-34 \cdot 7$ \\
\hline$\% B F\left(J P W_{7}\right)$ & $25 \cdot 1$ & $6 \cdot 6$ & $8 \cdot 2-35 \cdot 6$ & $20 \cdot 0$ & $4 \cdot 2$ & $8 \cdot 2-27 \cdot 8$ & 30.5 & 3.5 & $22 \cdot 5-35 \cdot 6$ \\
\hline \%BF(DW) & $32 \cdot 2$ & $6 \cdot 6$ & $11 \cdot 0-43 \cdot 5$ & $27 \cdot 8$ & 5.4 & $11 \cdot 0-37 \cdot 3$ & $36 \cdot 9$ & $4 \cdot 2$ & $26 \cdot 1-43 \cdot 5$ \\
\hline
\end{tabular}



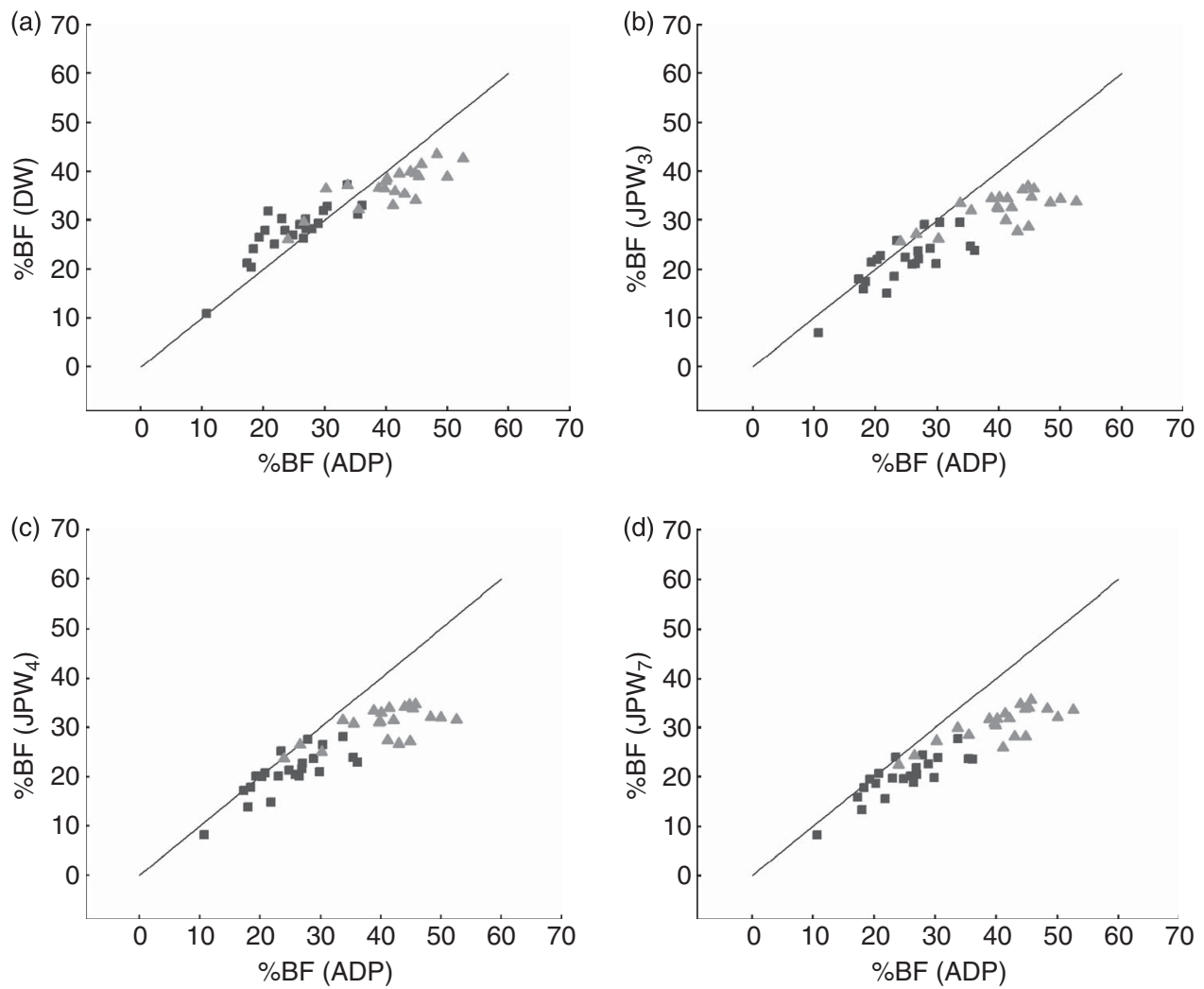

Fig. 1 Scatter plots showing percentage body fat (\%BF) estimated from different equations based on skinfold thickness measurements compared with that from air-displacement plethysmography (ADP) as the validating measure: (a) Durnin and Womersley (1974) four-site equation (DW); (b) Jackson, Pollock and Ward (1980) three-site equation (JPW 3 ); (c) Jackson et al. (1980) four-site equation (JPW ${ }_{4}$ ); and (d) Jackson et al. (1980) seven-site equation $\left(\mathrm{JPW}_{7}\right)$. Comparison performed for forty-three females aged 18-55 years from Dublin, Republic of Ireland among participants with $\mathrm{BMI}<25.0 \mathrm{~kg} / \mathrm{m}^{2}(\square ; n$ 22, group 2) and participants with $\mathrm{BMI} \geq 25.0 \mathrm{~kg} / \mathrm{m}^{2}$ ( $\Delta ; n 21$, group). The bias in skinfold-based measures can be visualized as departures from the lines of equality (diagonal lines). (a) CV of the root-mean-square error compared with ADP $\left(\mathrm{CV}_{\mathrm{RSME}}\right)=0.16$ for all participants (group 1), 0.16 for group 2 and 0.16 for group 3; (b) $\mathrm{CV}_{\mathrm{RSME}}=0.29$ for group 1, 0.24 for group 2 and 0.31 for group 3; (c) $\mathrm{CV}_{\mathrm{RSME}}=0.35$ for group $1,0.26$ for group 2 and 0.37 for group 3; (d) $C V_{\mathrm{RSME}}=0.35$ for group $1,0.30$ for group 2 and 0.36 for group 3

equations was significantly lower, $\mathrm{JPW}_{3} \quad(\% \mathrm{BF}=26 \cdot 8$ $(\mathrm{sD} 6 \cdot 9)), \mathrm{JPW}_{4}(\% \mathrm{BF}=25 \cdot 6(\mathrm{sD} 6 \cdot 9))$ and $\mathrm{JPW}_{7}(\% \mathrm{BF}=25 \cdot 1$ (SD 6.6)), compared with the reference method. When the estimates from the equations where compared with those of ADP, the $\mathrm{CV}_{\text {RMSE }}$ was $0 \cdot 16,0.29,0.35$ and 0.35 for DW, $\mathrm{JPW}_{3}, \mathrm{JPW}_{4}$ and $\mathrm{JPW}_{7}$, respectively. Thus, in group 1 , the DW result proved to be closer to the validation method of ADP. Of the JPW equations tested the lowest value of $\mathrm{CV}_{\mathrm{RMSE}}$ was for $\mathrm{JPW}_{3}$, indicating it to be the most accurate of the JPW equations. There was little difference in the $\mathrm{JPW}_{4}$ and $\mathrm{JPW}_{7}$ results when compared with ADP. The results are displayed graphically using scatter plots of the measures in Fig. 1.

In Table 2, group 2 participants with a BMI $<25 \cdot 0 \mathrm{~kg} / \mathrm{m}^{2}$ had an estimated mean \%BF of 24.8 (SD 6.3), $27 \cdot 8$ (SD 5.4), 21.6 (SD 5.2), 20.8 (SD 4.6) and 20.0 (SD 4.2) when using $\mathrm{ADP}, \mathrm{DW}, \mathrm{JPW}_{3}, \mathrm{JPW}_{4}$ and $\mathrm{JPW}_{7}$, respectively. Results indicate that when the entire group was tested for the $\mathrm{CV}_{\mathrm{RMSE}}$, the DW method again had the lowest $\mathrm{CV}_{\mathrm{RMSE}}$ at $0 \cdot 16$, indicating it was the most accurate equation for measuring \%BF. JPW methods became increasingly less accurate when more measurement sites were included in the equation (i.e. $0 \cdot 24,0 \cdot 26$ and 0.30 for $\mathrm{JPW}_{3}, \mathrm{JPW}_{4}$ and $\mathrm{JPW}_{7}$, respectively). The results are displayed graphically using scatter plots of the measures in Fig. 1. Although statistically non-significant $(P>0.05)$ in our sample, Fig. 1 suggests there may be some curvature in the JPW measures, thus the bias and accuracy of the JPW measures may change non-linearly with \%BF.

The mean $\%$ BF value for group $3\left(\mathrm{BMI} \geq 25 \cdot 0 \mathrm{~kg} / \mathrm{m}^{2}\right)$ was $40 \cdot 5$ (sD 7.2), 36.9 (sD 4.2), $32 \cdot 3$ (sD 3.4), $30 \cdot 7$ (sD 3.3) and $30.5(\mathrm{SD} 3.5)$ for $\mathrm{ADP}, \mathrm{DW}, \mathrm{JPW}_{3}, \mathrm{JPW}_{4}$ and $\mathrm{JPW}_{7}$, respectively. Results of the $\mathrm{CV}_{\text {RMSE }}$ again showed that DW had most accuracy with the lowest value $(0 \cdot 16)$. The JPW equations were again less reliable than the DW equation. In this group, the $\mathrm{JPW}_{3}$ equation was again the most accurate of the three $\left(0.31,0.37\right.$ and 0.36 for $\mathrm{JPW}_{3}, \mathrm{JPW}_{4}$ and $\mathrm{JPW}_{7}$, respectively). The results are displayed graphically using scatter plots of the measurements taken in Fig. 1. 
Table 3 Regression analysis results. Estimates of bias are presented for each equation used in the present study: Jackson, Pollock and Ward's (1980) three-, four- and seven-site equations (JPW $3, \mathrm{JPW}_{4}$ and $\mathrm{JPW}_{7}$, respectively) and Durnin and Womersley's (1974) four-site equation (DW), for estimating percentage body fat in forty-three females aged 18-55 years from Dublin, Republic of Ireland. Bias changepoint values (in parentheses) are expressed as a percentage

\begin{tabular}{lrrr}
\hline & \multicolumn{3}{c}{ Estimated bias (bias change-point, \%) } \\
\cline { 2 - 4 } Equation & All participants $(n$ 43) & $\mathrm{BMl}<25.0 \mathrm{~kg} / \mathrm{m}^{2}(n$ 22) & $\mathrm{BMl} \geq 25.0 \mathrm{~kg} / \mathrm{m}^{2}(n 21)$ \\
\hline $\mathrm{JPW}_{3}$ & $8.0-0.42 \times \% \mathrm{BF}(19)$ & $6.1-0.38 \times \% \mathrm{BF}(16)$ & $19.9-0.70 \times \% \mathrm{BF}(29)$ \\
$\mathrm{JPW}_{4}$ & $8 \cdot 2-0.46 \times \% \mathrm{BF}(18)$ & $6.5-0.42 \times \% \mathrm{BF}(15)$ & $19.4-0.72 \times \% \mathrm{BF}(27)$ \\
JPW $_{7}$ & $6.3-0.42 \times \% \mathrm{BF}(15)$ & $6.1-0.44 \times \% \mathrm{BF}(14)$ & $15.3-0.62 \times \% \mathrm{BF}(25)$ \\
DW & $13.5-0.42 \times \% \mathrm{BF}(32)$ & $10.2-0.29 \times \% \mathrm{BF}(35)$ & $18.1-0.54 \times \% \mathrm{BF}(34)$ \\
\hline
\end{tabular}

From simple linear regression analyses, estimates of bias in the skinfold thickness measurements of body fat are presented in Table 3. Bias in all of the skinfold measures was calculated for \%BF (as measured by ADP). All measurements showed a positive bias, which decreased as $\% \mathrm{BF}$ increased. For all study participants, the change-point (where bias $=0$ ) was at $32 \% \mathrm{BF}$ for $\mathrm{DW}$, indicating that DW overestimates \%BF when it is less than $32 \%$, but underestimates \%BF when it is greater than $32 \%$. The DW calculation has a restricted range and for any individual it is biased towards $32 \% \mathrm{BF}$. The change-point was much lower for the JPW measures, at a point where few data were available in this sample group (i.e. $<20 \% \mathrm{BF}$ ). This indicates a general underestimation of $\% \mathrm{BF}$ by all three JPW measures in our study population.

\section{Discussion}

The purpose of the present study was to compare the accuracy of anthropometric measurement-based equations for estimating \%BF against $\mathrm{ADP}$ in three groups: the overall female population regardless of BMI status and those with BMI either $<25.0 \mathrm{~kg} / \mathrm{m}^{2}$ or $\geq 25.0 \mathrm{~kg} / \mathrm{m}^{2}$. Moreover, we sought to identify which equation based on skinfold thickness measurements was most accurate for each group. In all three groups the DW method had a smaller $\mathrm{CV}_{\mathrm{RMSE}}$ (i.e. greater accuracy) than the JPW equations when compared with ADP, the criterion measure. Of the three JPW equations, $\mathrm{JPW}_{3}$ performed best when compared with ADP in all three tests.

While the DW equation maintained an accuracy level of $0 \cdot 16$ in the $\mathrm{CV}_{\text {RMSE }}$ across the general population and both BMI groups, the accuracy of the JPW equations fell considerably when the group with $\mathrm{BMI}<25 \cdot 0 \mathrm{~kg} / \mathrm{m}^{2}$ was compared against the group with BMI $\geq 25 \cdot 0 \mathrm{~kg} / \mathrm{m}^{2}\left(\mathrm{JPW}_{3}\right.$ : $0.24 v .0 .31, \mathrm{JPW}_{4}: 0.26$ v. $0.37, \mathrm{JPW}_{7}: 0.30$ v. 0.36 , respectively). One possible explanation for such bias in the JPW equations in participants having a higher BMI resides in the comparison of the mean body densities and their corresponding \%BF results of both the original DW and JPW studies (i.e. 1974 and 1980, respectively). DW validated their equation on 272 females aged $17-68$ years with mean body density of $1.028 \mathrm{~g} / \mathrm{cm}^{3}$ that corresponds to $\% \mathrm{BF}$ of $31 \%$. The equations of JPW were validated on 249 females aged 18-55 years with mean body density of $1.044 \mathrm{~g} / \mathrm{cm}^{3}$ corresponding to $\% \mathrm{BF}$ of $24 \%{ }^{(15)}$. This significant difference in the mean \%BF of participants of both studies can explain why the change-point (where bias $=0$ ) is at $32 \% \mathrm{BF}$ for DW and is much lower for the JPW equations (i.e. $<20 \% \mathrm{BF}$ ) and results in a general underestimation of \%BF by all three JPW measures in our study population. This underestimation is in line with data published by others. Accessible and simple methods such as bioelectrical impedance analysis (BIA) or skinfold thickness measurements often provide different results when compared with relatively new and costly equipment such as dual-energy X-ray absorptiometry (DXA). For instance, in men aged 18-62 years, Ball et al. (2004) compared three anthropometric body composition prediction equations (i.e. Jackson and Pollock, 1978; 1985) with DXA. Their results showed a 3\% underestimation of the three equations compared with DXA ${ }^{(21)}$. Further, in an adolescent population (age 13-17 years) \%BF has been reported to be significantly lower when estimated from anthropometry (i.e. nine skinfolds, see reference 24) and compared with Bod Pod ${ }^{(25)}$.

In a group of 653 university students, including 190 males and 463 females (age 18-30 years), Arroyo et al. (2004) reported that anthropometric equations underestimated \%BF when compared with BIA. In the female group, the \%BF measured by BIA was $29 \%$ whereas it was $26 \cdot 2 \%, 26 \cdot 0 \%, 25 \cdot 2 \%$ and $24.3 \%$ when estimated from Brozek, Deurenberg, Lean and Siri equations, respectively. In the male group, the \%BF measured by BIA was also higher (i.e. 20\%) when compared with estimation from anthropometric equations (i.e. $16 \cdot 1 \%, 16.7 \%$ and $15.9 \%$ from Brozek, Deurenberg and Siri equations, respectively) ${ }^{(26)}$.

Sun et al. (2005) reported that BIA underestimated \%BF in a large group of men and women ( $n$ 591; age 19-60 years). Averaged \%BF values were $32.9 \%$ and $34.7 \%$ as measured by BIA and DXA, respectively ${ }^{(27)}$.

A comparison of BMI-defined overweight and obese individuals tested by the Jackson and Pollock method in the 1999-2002 National Health and Nutrition Examination Survey (NHANES) cohort indicated that substantial body composition changes have occurred in men and women in 
the USA since these equations were originally formulated ${ }^{(28)}$. The NHANES examines a nationally representative sample of approximately 5000 persons each year ${ }^{(29)}$. The proportion of those tested by Jackson and Pollock who were overweight or obese (BMI $\geq 25.0 \mathrm{~kg} / \mathrm{m}^{2}$ ) was $42 \%$ and $7 \%$, respectively. In contrast, the percentage of American men and women from the 1999-2002 NHANES with $\mathrm{BMI} \geq 25.0 \mathrm{~kg} / \mathrm{m}^{2}$ in $1999-2002$ was substantially higher, $67 \%$ and $62 \%$ respectively. These comparative data also indicate that the increase in overweight and obesity is greater in women than in men ${ }^{(28)}$. The JPW equations were derived from a population of lean to moderately obese participants and can be expected to lose their precision when performed on a population with a higher \%BF. The mean \%BF of the JPW study (24\%) is considerably lower than that tested in the DW study (31\%) and in the current study $(32.7 \%)$. The findings of comparative studies (i.e. Flegal and Troiano, $2000^{(28)}$ ) suggest that the mean \%BF determined in the present study and in the DW study are more representative of modern Western populations. Therefore the JPW equations may no longer be suitable for use in groups similar to those investigated in the present study. Support for this comes from studies providing modified or new anthropometric equations for ethnically diverse young adults (17-35 years) $)^{(12,30)}$ or older South Asian individuals (30-65 years) ${ }^{(31)}$. Nevill et al. (2008) ${ }^{(4)}$ have recommended that caution should be exercised when predicting body fat using the Jackson and Pollock quadratic equations for subjects with sums of skinfolds $>120 \mathrm{~mm}$. Our study findings further substantiate Nevill et al.'s recommendation. Caution should be exercised when using JPW sites to measure the \%BF of participants with a BMI of $\geq 25.0 \mathrm{~kg} / \mathrm{m}^{2}$ due to the tendency of these equations to underestimate $\% \mathrm{BF}$ in those with a $\% \mathrm{BF}>20$.

Clearly a limitation exists with statistically derived formulas as their application is intended for a broad sample of individuals, which paradoxically leads to inherent inaccuracies. The ideal statistical estimation method for an individual is based on a sample of similar individuals. As can be seen from the results of the current study, all measures show a positive bias; the change-point is dictated by the mean $\% \mathrm{BF}$ of the group and so a reduction of the bias in any equation is possible if the equation is based on a less general and more specific group measurement. If a linear regression equation is derived from a group having similar BMI such as $25 \cdot 0-29.9 \mathrm{~kg} / \mathrm{m}^{2}$ then when this equation is applied to an individual within the same BMI category there will be less bias in the resulting \%BF estimate.

The results of the present study indicate that the DW equation shows less bias and more accuracy when compared with the JPW equations. One possible reason for this is that the DW is an age-specific equation and thus is based on a more closely related sample group than its JPW counterpart, which is non-age specific. The original DW study (1974) indicated that body density in females corresponding to a total of four skinfold thicknesses decreased by about $0.15 \times 10^{3} \mathrm{~kg} / \mathrm{m}^{3}$ between early adulthood and the ' $50+$ ' group by about $0.004 \times 10^{3} \mathrm{~kg} / \mathrm{m}^{3}$ per decade ${ }^{(14)}$.

The DW equation also proves more useful in the general population because it includes a broader age category (16-72 years). The JPW equation has been tested in participants ranging from 18 to 55 years of age and its accuracy, if performed on those outside this age bracket, is unknown. Furthermore, considering the rising levels of obesity in society and the subsequent need for simple and effective field methods to estimate \%BF among different BMI groups, it would appear that further studies would be worthwhile to develop more accurate body composition equations than those most commonly used at present (i.e. DW and JPW). Future research should be aimed at validating a suitable regression equation for use in each of the different BMI categories (i.e. underweight, normal weight, overweight and obese). Such equations could be easily applied in field settings and/or in large-scale studies, thus providing a more accurate \%BF estimate with less bias than those equations currently in common use.

\section{Conclusion}

To the best of our knowledge, the present study is the first one to: (i) compare the estimates of \%BF provided by the most commonly used skinfold thickness-based equations against whole-body ADP; and (ii) investigate the most effective anthropometric method for estimating \%BF using the BMI scale as an initial indicator of body fat status in female participants aged between 18 and 55 years. The data presented suggest that the original skinfold thicknessbased equations of Durnin and Womersley $(1974)^{(14)}$ provide a more accurate result than the Jackson, Pollock and Ward (1980) $)^{(13)}$ equations when estimating \%BF. In all groups the DW equation had a lower $\mathrm{CV}_{\mathrm{RMSE}}(0 \cdot 16)$ than the JPW equations when compared with ADP; of the three JPW equations the three-site equation had the lowest $\mathrm{CV}_{\text {RMSE }}$ when compared with ADP in all three tests. We conclude that, in comparison to ADP, the DW equation is the most accurate method to estimate \%BF in female participants across the three groups investigated herein.

\section{Acknowledgements}

Acknowledgements: The authors offer sincere thanks to all of the volunteers for their participation in this study and also to the Institute for Sports and Health, University College Dublin for allowing the use of their equipment and laboratory for subject testing. This work was performed within the context of a Masters Degree in Exercise and Nutrition Science undertaken by D.T. in association with the University of Chester, UK. Financial support: This research received no specific grant from any funding 
agency in the public, commercial or not-for-profit sectors. R.D. and M.C.W. are employed by University College Dublin. P.D. and A.T.B. are employed by the Royal College of Surgeons in Ireland. Conflict of interest: None. Authorship: D.T. performed data collection, data analysis and manuscript writing; R.D. advised on and oversaw data collection and manuscript writing. M.C.W. advised on data collection and manuscript writing; P.D. provided key statistical support including power calculations and data analysis. A.T.B. advised on study design, manuscript editing and was originator of the initial experimental hypothesis. A.T.B. is corresponding author for the study. All authors contributed to the revision and final approval of the paper. Ethics of buman subject participation: The study was conducted according to the guidelines laid down in the Declaration of Helsinki and all procedures involving human participants were approved by the University College Dublin Human Research Ethics Committee. Written informed consent was obtained from all participants.

\section{References}

1. Reilly T (1996) Fitness assessment. In Science and Soccer, pp. 25-49 [T Reilly, editor]. London: E \& FN Spon.

2. National Heart, Lung, and Blood Institute in cooperation with The National Institute of Diabetes and Digestive and Kidney Diseases (1998) Clinical guidelines on the identification, evaluation, and treatment of overweight and obesity in adults - The Evidence Report. http://www.nhlbi.nih.gov/ guidelines/obesity/ob_gdlns.pdf (accessed August 2012).

3. Kelly T, Yang W, Chen CS et al. (2008) Global burden of obesity in 2005 and projections to 2030. Int J Obes (Lond) 32, 1431-1437.

4. Nevill A, Metsios G, Jackson A et al. (2008) Can we use the Jackson and Pollock equations to predict body density/fat of obese individuals in the 21st century? Int J Body Compost Res 6, 114-121.

5. Fields D, Goran M \& McCrory M (2002) Body-composition assessment via air-displacement plethysmography in adults and children: a review. Am J Clin Nutr 75, 453-467.

6. Dewit O, Fuller NJ, Fewtrell MS et al. (2000) Whole body air displacement plethysmography compared with hydrodensitometry for body composition analysis. Arch Dis Child 82, 159-164.

7. Noreen E \& Lemon P (2006) Reliability of air displacement plethysmography in a large, heterogeneous sample. Med Sci Sports Exerc 38, 1505-1509.

8. Watts K, Naylor LH, Davis EA et al. (2006) Do skinfolds accurately assess changes in body fat in obese children and adolescents? Med Sci Sports Exerc 38, 439-444.

9. Ginde S, Geliebter A, Rubiano F et al. (2005) Air displacement plethysmography: validation in overweight and obese subjects. Obes Res 13, 1232-1237.

10. Heyward V (2001) ASEP methods recommendation: body composition assessment. JEPonline 4, 1-12.

11. Heyward V (1998) Practical body composition assessment for children, adults, and older adults. Int J Sport Nutr 8, 285-307.

12. Jackson AS, Ellis KJ, McFarlin BK et al. (2009) Crossvalidation of generalised body composition equations with diverse young men and women: the Training Intervention and Genetics of Exercise Response (TIGER) Study. Br J Nutr 101, 871-878.

13. Jackson A, Pollock M \& Ward A (1980) Generalized equations for predicting body density of women. Med Sci Sport Exerc 12, 175-181.

14. Durnin J \& Womersley J (1974) Body fat assessed from total body density and its estimation from skinfold thickness: measurements on 481 men and women aged from 16 to 72 years. Br J Nutr 32, 77-97.

15. Teran C, Sparks K, Quinn L et al. (1991) Percent body fat in obese white females predicted by anthropometric measurements. Am J Clin Nutr 53, 7-13.

16. Peterson M, Czerwinski S \& Siervogel R (2003) Development and validation of skinfold-thickness prediction equations with a 4-compartment model. Am J Clin Nutr 77, 1186-1191.

17. Michels N, Huybrechts I, Bammann K et al. (2013) Caucasian children's fat mass: routine anthropometry $v$. air-displacement plethysmography. Br J Nutr 109, 1528-1537.

18. Edholm O, Adam J \& Best T (1974) Day-to-day weight changes in young men. Ann Hum Biol 1, 3-12.

19. Bunt J, Lohman $T$ \& Boileau $R$ (1989) Impact of total body water fluctuations on estimation of body fat from body density. Med Sci Sports Exerc 21, 96-100.

20. Hawes R \& Martin D (2001) Human body composition. In Kinanthropometry and Exercise Physiology Laboratory Manual: Tests, Procedures and Data, pp. 7-46 [R Eston and T Reilly, editors]. London: Routledge.

21. Ball S, Altena T \& Swan P (2004) Comparison of anthropometry to DXA: a new prediction equation for men. Eur J Clin Nutr 58, 1525-1531.

22. Dempster P \& Aitkens S (1995) A new air displacement method for the determination of human body composition. Med Sci Sports Exerc 27, 1692-1697.

23. Siri WE (1961) Body composition from fluid space and density. In Techniques for Measuring Body Composition, pp. 223-244 [J Brozek and A Hanschel, editors]. Washington, DC: National Academy of Science.

24. Slaughter MH, Lohman TG, Boileau RA et al. (1988) Skinfold equations for estimation of body fatness in children and youth. Hum Biol 60, 709-723.

25. Vicente-Rodríguez G, Rey-López J, Mesana M et al. (2012) Reliability and intermethod agreement for body fat assessment among two field and two laboratory methods in adolescents. Obesity (Silver Spring) 20, 221-228.

26. Arroyo M, Rocandio A, Ansotegui L et al. (2004) Comparison of predicted body fat percentage from anthropometric methods and from impedance in university students. $\mathrm{Br} \mathrm{J}$ Nutr 92, 827-832.

27. Sun G, French C, Martin G et al. (2005) Comparison of multifrequency bioelectrical impedance analysis with dualenergy X-ray absorptiometry for assessment of percentage body fat in a large, healthy population. Am J Clin Nutr 81, 74-78.

28. Flegal K \& Troiano R (2000) Changes in the distribution of body mass index of adults and children in the US population. Int J Obes Relat Metab Disord 24, 807-818.

29. Centers for Disease Control and Prevention (2012) About the National Health and Nutrition Examination Survey. http://www.cdc.gov/nchs/nhanes/about_nhanes. htm (accessed August 2012).

30. O'Connor D, Bray M, McFarlin B et al. (2010) Generalized equations for estimating DXA percent fat of diverse young women and men: the TIGER study. Med Sci Sports Exerc $\mathbf{4 2}$, 1959-1965.

31. Kohli S, Gao M \& Lear S (2009) Using simple anthropometric measures to predict body fat in South Asians. Appl Physiol Nutr Metab 34, 40-48. 